\title{
Thermal and Electrical Transport Properties of Zr-Based Bulk Metallic Glassy Alloys with High Glass-Forming Ability
}

\author{
Rie Y. Umetsu*, Rong Tu and Takashi Goto \\ Institute for Materials Research, Tohoku University, Sendai 980-8577, Japan
}

Thermal and electrical transport properties, such as thermal diffusivity, the electrical resistivity and thermopower of the Zr-based bulk metallic glassy (BMG) alloys of $\mathrm{Zr}_{42} \mathrm{Cu}_{42} \mathrm{Ag}_{8} \mathrm{Al}_{8}$ and $\mathrm{Zr}_{55} \mathrm{Al}_{10} \mathrm{Cu}_{35-x} \mathrm{Ni}_{x}$ ( $x=0,5$ and 10) with high glass-forming ability were investigated. Thermal diffusivity is comparatively low at about $2 \times 10^{-6} \mathrm{~m}^{2} \mathrm{~s}^{-1}$, reflecting the aperiodic crystal structure of the BMG, whereas it becomes higher and depends on the alloy compositions after their crystallization. The phonon contribution to the thermal conductivity of the BMG alloys is thought to be small, based on a comparison with the estimated value of the electronic contribution to the thermal conductivity from the Wiedemann-Franz law. The thermopower of the present Zr-based BMG alloys shows a small positive value around room temperature, which is a general feature of nonmagnetic amorphous alloys. [doi:10.2320/matertrans.M2012163]

(Received May 7, 2012; Accepted July 17, 2012; Published September 5, 2012)

Keywords: bulk metallic glass, thermal diffusivity, glass transition, electrical resistivity, thermopower

\section{Introduction}

Metallic glasses are generally produced from the undercooled liquid state by rapid cooling. ${ }^{1)}$ Inoue et al. have found that bulk metallic glassy (BMG) alloys can be obtained even by conventional casting techniques at relatively slow cooling rates, and have also reported that a number of metallic glasses can be formed by quenching in $\mathrm{Zr}-\mathrm{Cu}, \mathrm{Ni}-\mathrm{Zr}, \mathrm{Pd}-\mathrm{Cu}$ alloy systems. $^{2-4)}$ As summarized by Inoue, BMG alloys exhibit three common features as follows: (1) They mostly belong to multicomponent systems, (2) they have significant atomic size ratios of above $12 \%$, and (3) they exhibit negative heats of mixing among the constituent elements. The satisfaction of these principles leads to a high glass transition temperature, $T_{\mathrm{g}}$ and a low liquidus temperature. The popularity of those materials was partly driven by the hope of developing promising materials for future applications, as well as by the scientific desire to understand the formation and the structure of amorphous solids. Since it is known that BMG alloys exhibit great strength, hardness, toughness, corrosion resistance and elasticity, they have been intensively investigated as good candidates for linear actuators, fuel-cell separators, biomedical materials, aircraft parts, sporting goods and so on.

On the other hand, from an academic viewpoint, it has been controversial as to why BMG alloys are formed under the above features. Unlike general amorphous alloys, $T_{\mathrm{g}}$, is clearly observed below the crystallization temperature, $T_{\mathrm{x}}$, in $\mathrm{BMG}$ alloys. The width of the supercooled liquid region is defined as the temperature difference, namely, $\Delta T=T_{\mathrm{x}}-T_{\mathrm{g}}$, and the glass forming ability is often discussed in consideration of the values of $\Delta T$. Studies of the thermophysical properties are required to clarify the glass formation mechanism and to estimate the critical cooling rate for the formation of metallic glass and the critical heating rate for heating amorphous solid without devitrification. Therefore, it is very important to investigate the thermophysical properties of the BMG alloys. In addition, it is generally known that the transport properties, such as electrical resistivity and thermopower, for the non-periodic materials are different to that for

*Correspondence author, E-mail: rieume@imr.tohoku.ac.jp the crystalline alloys with have periodic structures because these transport properties are governed by the conduction electrons around the Fermi energy. Especially, electronic states for the BMG alloys have been interested from the view points that there might be a correlation between the glass phase stability and the electronic structures. ${ }^{5-7)}$ Although a huge number of the investigations for the transport properties have been carried out in the amorphous alloys so far, systematic studies for these physical properties in the BMG alloys would make to help the understanding of their electronic states. Therefore, in this study, thermal diffusivity, electrical resistivity, and the thermopower of $\mathrm{Zr}$-based $\mathrm{BMG}$ alloys of $\mathrm{Zr}_{42} \mathrm{Cu}_{42} \mathrm{Ag}_{8} \mathrm{Al}_{8}$ and $\mathrm{Zr}_{55} \mathrm{Al}_{10} \mathrm{Cu}_{35-x} \mathrm{Ni}_{x}$ ( $x=0,5$ and 10) with high glass-forming ability were investigated.

\section{Experimental Procedures}

Specimens of $\mathrm{Zr}_{42} \mathrm{Cu}_{42} \mathrm{Ag}_{8} \mathrm{Al}_{8}$ and $\mathrm{Zr}_{55} \mathrm{Al}_{10} \mathrm{Cu}_{35-x} \mathrm{Ni}_{x}$ $(x=0,5$ and 10) alloys were prepared by arc melting in a Zr-gettered argon atmosphere for a mixture of constituent elements with the desired compositions. The alloy ingots were completely remelted and cast into cylindrical rod samples with diameters of $10 \mathrm{~mm}$ by the copper mold tiltcasting method. The glassy phase was identified by X-ray diffraction (XRD) and differential scanning calorimetly (DSC) in a flow of purified argon. The heating rate during the DSC measurement was about $0.33 \mathrm{~K} \cdot \mathrm{s}^{-1}$. The thermal diffusivity was measured in the temperature range of $300-$ $873 \mathrm{~K}$ with an ULVAC-RIKO TC-7000 Standard Laser Flash Thermal Constants Analyzer using disc specimens $10 \mathrm{~mm}$ in diameter and $2 \mathrm{~mm}$ in width. The method of thermal diffusivity calculation was similar way to that of Yamasaki et al., details of which can be found in the literature. ${ }^{89}$ ) The electrical resistivity was measured by a conventional four probe method, and the thermopower was investigated by measurement of the temperature difference of the power voltage between two Pt probes attached to the specimens, which were cut so as to be about $2 \times 2 \times 8 \mathrm{~mm}$ in size. Density was measured by substitution method with $\mathrm{He}$ gas with using a SHIMADZU-Gas Pycnometer AccuPyc-1330. 

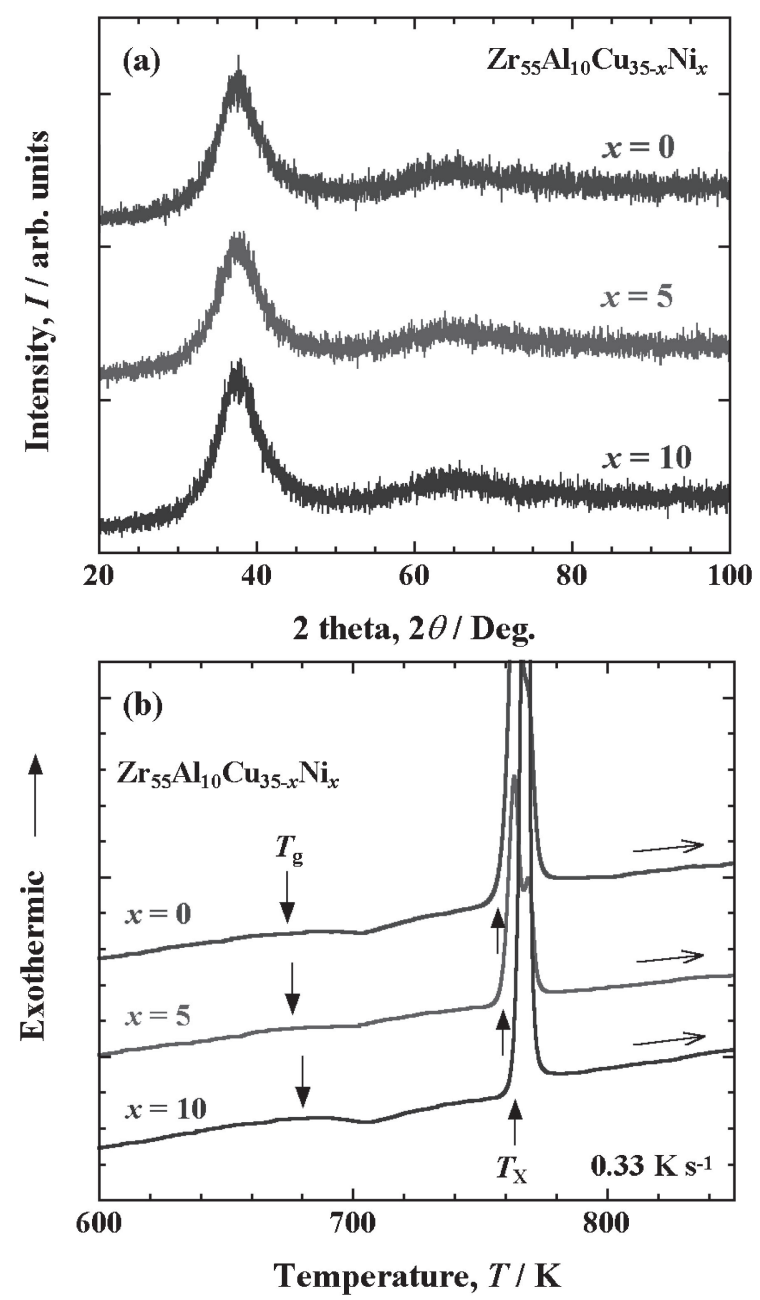

Fig. 1 (a) X-ray diffraction patterns measured at room temperature and (b) differential scanning calorimetric heating curves of $\mathrm{Zr}_{55} \mathrm{Al}_{10} \mathrm{Cu}_{35-x} \mathrm{Ni}_{x}$ $(x=0,5$ and 10) bulk metallic glassy alloys.

\section{Experimental Results and Discussions}

Figures 1(a) and 1(b) indicate XRD patterns measured at room temperature with $10 \mathrm{~mm}$ disc specimens and DSC heating curves of $\mathrm{Zr}_{55} \mathrm{Al}_{10} \mathrm{Cu}_{35-x} \mathrm{Ni}_{x} \quad(x=0,5$ and 10) measured at a rate of $0.33 \mathrm{~K} \mathrm{~s}^{-1}$, respectively. In the Fig. 1(a), only a broad peak associated to the formation of a glassy phase is seen. In the DSC heating curves of the Fig. 1(b), an endothermic reaction and a sharply peaked exothermic one, which are ascribed to the glass transition and crystallization, respectively, are clearly observed. The glass transition temperature, $T_{\mathrm{g}}$, and crystallization temperature, $T_{\mathrm{x}}$, are indicated by the arrows in the figure, in which $T_{\mathrm{g}}$ and $T_{\mathrm{x}}$ are defined as the beginning of the endothermic and exothermic reactions with increasing temperature, respectively. The $T_{\mathrm{g}}$ and $T_{\mathrm{x}}$ for $x=0$ are deduced to be about 674 and $757 \mathrm{~K}$, respectively, and slightly increase with increasing Ni content. These obtained values and behavior accord with the literature. ${ }^{10,11)}$ Figures 2(a) and 2(b) also show the XRD pattern measured at room temperature with a $10 \mathrm{~mm}$ disc specimen and the DSC heating curve of $\mathrm{Zr}_{42} \mathrm{Cu}_{42} \mathrm{Ag}_{8} \mathrm{Al}_{8}$ alloy, respectively. The endothermic and exothermic reactions, being attributed to the glass transition and crystallization, are observed, and $T_{\mathrm{g}}$ and $T_{\mathrm{x}}$ for $\mathrm{Zr}_{42} \mathrm{Cu}_{42} \mathrm{Ag}_{8} \mathrm{Al}_{8}$ are
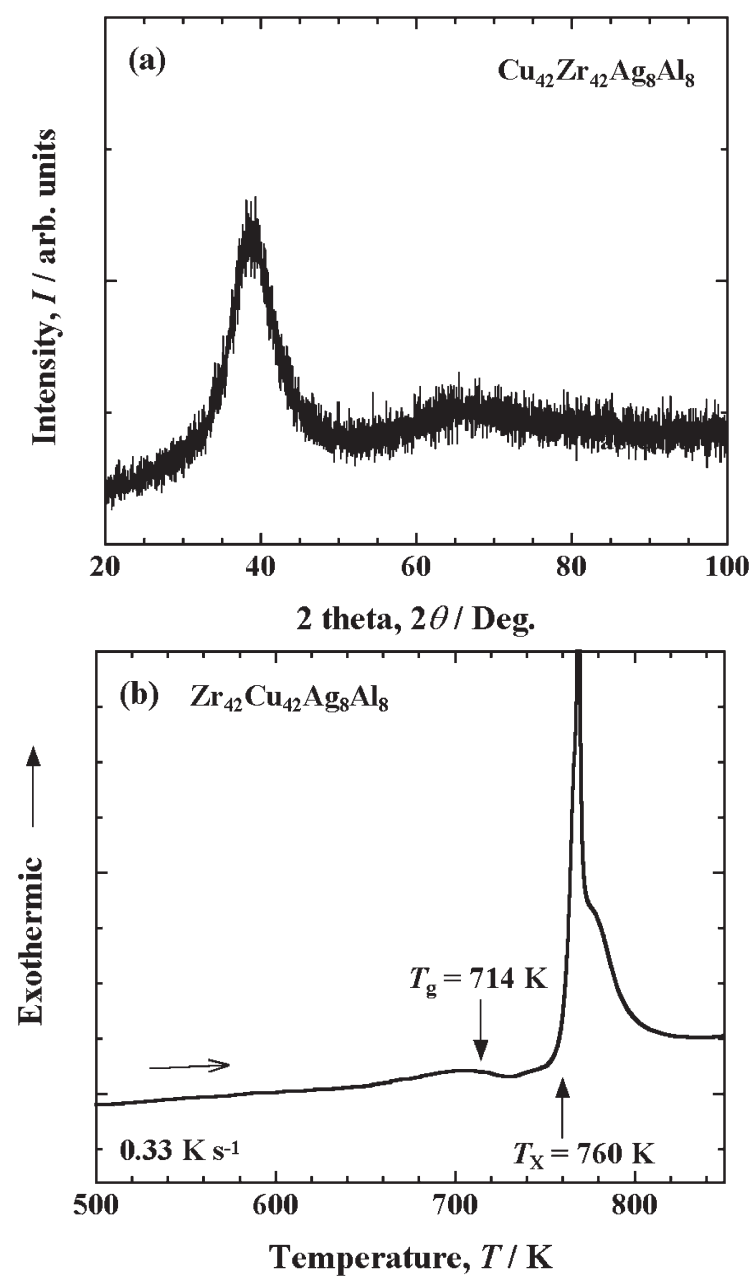

Fig. 2 (a) X-ray diffraction pattern measured at room temperature and (b) differential scanning calorimetric heating curve of $\mathrm{Zr}_{42} \mathrm{Cu}_{42} \mathrm{Ag}_{8} \mathrm{Al}_{8}$ bulk metallic glassy alloy.

714 and $760 \mathrm{~K}$, respectively, being comparable to the similar composition of $\mathrm{Zr}-\mathrm{Cu}-\mathrm{Ag}-\mathrm{Al}$ cast alloy. ${ }^{12)}$

Temperature dependences of the thermal diffusivity of $\mathrm{Zr}_{42} \mathrm{Cu}_{42} \mathrm{Ag}_{8} \mathrm{Al}_{8}$ and $\mathrm{Zr}_{55} \mathrm{Al}_{10} \mathrm{Cu}_{35-x} \mathrm{Ni}_{x}(x=0,5$ and 10) bulk metallic glassy (BMG) alloys are indicated in Fig. 3. It should be noticed that the thermal diffusivity of the alloys at room temperature is comparable to be about $2.0 \times$ $10^{-6} \mathrm{~m}^{2} \mathrm{~s}^{-1}$. The value of $x=5$ has been already reported and is in good agreement. ${ }^{8)}$ In the present study, the thermal diffusivity of $\mathrm{Zr}_{55} \mathrm{Al}_{10} \mathrm{Cu}_{35-x} \mathrm{Ni}_{x}$ alloys was investigated by changing $\mathrm{Ni}$ concentration, and the results show that the thermal diffusivity of $\mathrm{Zr}_{55} \mathrm{Al}_{10} \mathrm{Cu}_{35-x} \mathrm{Ni}_{x}$ BMG alloys is not sensitive to $x$, whereas that of crystallized $\mathrm{Zr}_{55} \mathrm{Al}_{10} \mathrm{Cu}_{35-x} \mathrm{Ni}_{x}$ alloys depends on the $x$. Similar values of the thermal diffusivity of the $\mathrm{BMG}$ alloys have been reported by systematic study in $\mathrm{Pd}_{40} \mathrm{Cu}_{40-x} \mathrm{Ni}_{x} \mathrm{P}_{20} \quad(x=0,10$ and 40). ${ }^{13,14)}$ Nishi et al. have investigated the thermal diffusivity also in the liquid state with using the vertical-type laser flash apparatus and have pointed out that there is a correlation between the value of the thermal diffusivity in the liquid state and the glass-forming ability. ${ }^{13)}$ The absolute value of the thermal conductivity, $K$, is given by a product of the thermal diffusivity, $\alpha$, specific heat, $C_{\mathrm{p}}$, and density, $d$, as follows; 
Table 1 Electrical resistivity $\rho$, thermopower $S$, thermal diffusivity $\alpha$, specific heat $C_{\mathrm{p}}$, thermal conductivity $K$, electronic contribution to the thermal conductivity $K_{\mathrm{el}}$, estimated from the Wiedemann-Franz law of $\mathrm{Zr}_{42} \mathrm{Cu}_{42} \mathrm{Ag}_{8} \mathrm{Al}_{8}$ and $\mathrm{Zr}_{55} \mathrm{Al}_{10} \mathrm{Cu}_{35-x} \mathrm{Ni}_{x}(x=0,5$ and 10$)$ bulk metallic glassy (BMG) alloys and those of their crystallized (Crys) alloys.

\begin{tabular}{|c|c|c|c|c|c|c|c|c|c|c|c|c|}
\hline \multirow{2}{*}{ Alloys } & \multicolumn{2}{|c|}{$\rho / 10^{-8} \Omega \cdot \mathrm{m}$} & \multicolumn{2}{|c|}{$S / 10^{-6} \mathrm{VK}^{-1}$} & \multicolumn{2}{|c|}{$\alpha / 10^{-6} \mathrm{~m}^{2} \mathrm{~s}^{-1}$} & \multicolumn{2}{|c|}{$C_{\mathrm{p}} / \mathrm{Jg}^{-1} \mathrm{~K}^{-1}$} & \multicolumn{2}{|c|}{$K / \mathrm{W} \mathrm{m}^{-1} \mathrm{~K}^{-1}$} & \multicolumn{2}{|c|}{$K_{\mathrm{el}} / \mathrm{W} \mathrm{m}^{-1} \mathrm{~K}^{-1}$} \\
\hline & $\mathrm{BMG}$ & Crys & BMG & Crys & $\mathrm{BMG}$ & Crys & BMG & Crys & BMG & Crys & BMG & Crys \\
\hline $\mathrm{Zr}_{42} \mathrm{Cu}_{42} \mathrm{Ag}_{8} \mathrm{Al}_{8}$ & 171 & 121 & 2.0 & 4.4 & 2.1 & $\sim 3.0$ & 0.31 & $\sim 0.29$ & 4.8 & $\sim 6.5$ & 4.3 & 6.1 \\
\hline $\begin{array}{c}\mathrm{Zr}_{55} \mathrm{Al}_{10} \mathrm{Cu}_{35} \\
(x=0)\end{array}$ & 188 & 67 & 1.8 & 4.4 & 2.3 & $\sim 6.5$ & 0.31 & $\sim 0.28$ & 4.8 & $\sim 12.5$ & 3.9 & 11.0 \\
\hline $\begin{array}{c}\mathrm{Zr}_{55} \mathrm{Al}_{10} \mathrm{Cu}_{30} \mathrm{Ni}_{5} \\
(x=5)\end{array}$ & $\begin{array}{l}176 \\
189^{8)}\end{array}$ & 71 & 1.7 & 5.5 & $\begin{array}{l}2.2 \\
2.2^{8)}\end{array}$ & 5.6 & 0.32 & 0.29 & $\begin{array}{l}4.8 \\
5.02^{8)}\end{array}$ & 11.2 & 4.2 & 10.4 \\
\hline $\begin{array}{c}\mathrm{Zr}_{55} \mathrm{Al}_{10} \mathrm{Cu}_{25} \mathrm{Ni}_{10} \\
(x=10)\end{array}$ & 166 & 78 & 2.2 & 10.1 & 2.1 & $\sim 5.0$ & 0.33 & $\sim 0.30$ & 4.7 & $\sim 10.3$ & 4.4 & 9.4 \\
\hline
\end{tabular}

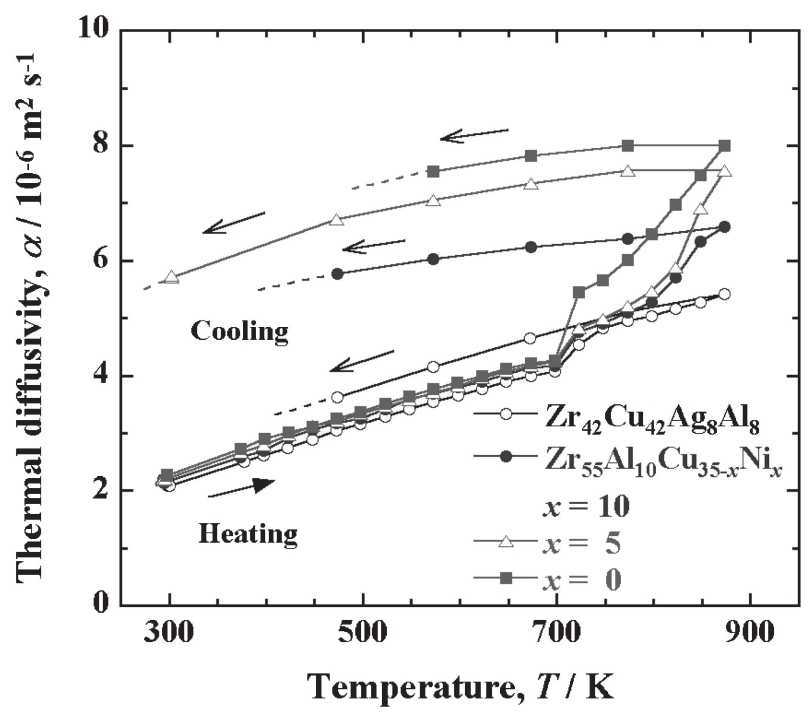

Fig. 3 Temperature dependence of the thermal diffusivity of $\mathrm{Zr}_{55} \mathrm{Al}_{10^{-}}$ $\mathrm{Cu}_{35-x} \mathrm{Ni}_{x}(x=0,5$ and 10$)$ and $\mathrm{Zr}_{42} \mathrm{Cu}_{42} \mathrm{Ag}_{8} \mathrm{Al}_{8}$ bulk metallic glassy alloys.

Table 2 Densities $d$, of $\mathrm{Zr}_{42} \mathrm{Cu}_{42} \mathrm{Ag}_{8} \mathrm{Al}_{8}$ and $\mathrm{Zr}_{55} \mathrm{Al}_{10} \mathrm{Cu}_{35-x} \mathrm{Ni}_{x}(x=0,5$ and 10 ) bulk metallic glassy (BMG) alloys and those of their crystallized (Crys) alloys.

\begin{tabular}{ccc}
\hline & $\begin{array}{c}d / 10^{3} \mathrm{~kg} \mathrm{~m}^{-3} \\
\mathrm{BMG}\end{array}$ & $\begin{array}{c}d / 10^{3} \mathrm{~kg} \mathrm{~m}^{-3} \\
\mathrm{Crys}\end{array}$ \\
\hline $\begin{array}{c}\mathrm{Zr}_{42} \mathrm{Cu}_{42} \mathrm{Ag}_{8} \mathrm{Al}_{8} \\
\mathrm{Zr}_{55} \mathrm{Al}_{10} \mathrm{Cu}_{35} \\
(x=0)\end{array}$ & 7.34 & 7.46 \\
$\mathrm{Zr}_{55} \mathrm{Al}_{10} \mathrm{Cu}_{30} \mathrm{Ni}_{5}$ & 6.80 & 6.87 \\
$(x=5)$ & 6.82 & 6.88 \\
$\mathrm{Zr}_{55} \mathrm{Al}_{10} \mathrm{Cu}_{25} \mathrm{Ni}_{10}$ & & \\
$(x=10)$ & 6.81 & 6.86 \\
\hline
\end{tabular}

$$
K=\alpha C_{\mathrm{p}} d .
$$

The values of $K, \alpha$ and $C_{\mathrm{p}}$ are listed in Table 1 , and those of $d$ in Table 2. These obtained values are discussed later.

Figures 4(a) and 4(b) indicate XRD patterns measured at room temperature of specimens for $\mathrm{Zr}_{55} \mathrm{Al}_{10} \mathrm{Cu}_{35-x} \mathrm{Ni}_{x}(x=0$, 5 and 10) and $\mathrm{Zr}_{42} \mathrm{Cu}_{42} \mathrm{Ag}_{8} \mathrm{Al}_{8}$ alloys after heating up to $873 \mathrm{~K}$; that is, these specimens are the same ones used for the XRD measurements of Figs. 1(a) and 2(a) and the thermal
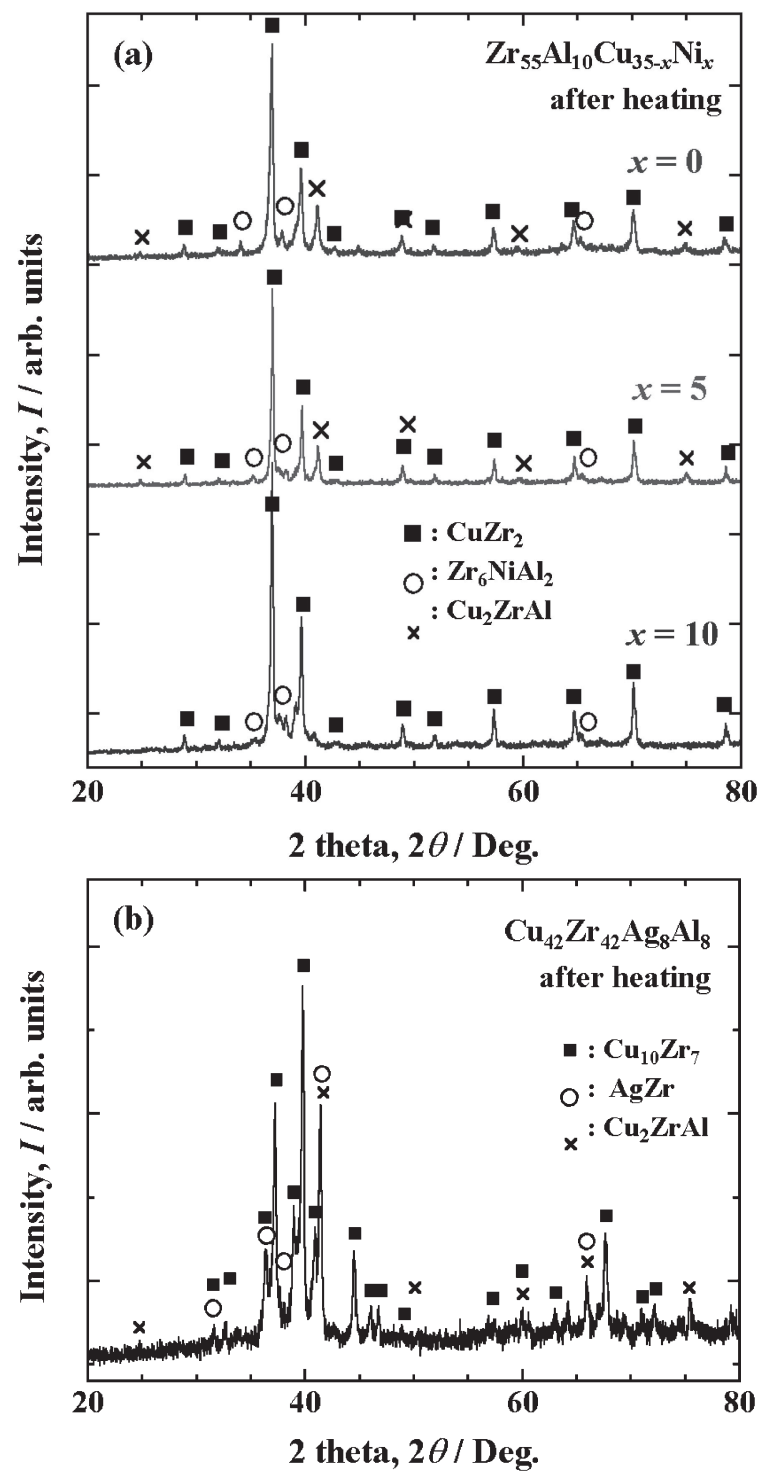

Fig. 4 X-ray diffraction patterns measured at room temperature of the specimens after heating up to $873 \mathrm{~K}$ (a) and that of $\mathrm{Zr}_{42} \mathrm{Cu}_{42} \mathrm{Ag}_{8} \mathrm{Al}_{8}$ (b).

diffusivity measurements of Fig. 3. These patterns clearly exhibit crystallized ones, and peaks of the crystallized $\mathrm{Zr}_{55} \mathrm{Al}_{10} \mathrm{Cu}_{35-x} \mathrm{Ni}_{x}(x=0,5$ and 10) alloys are indexed as a mixed phase of $\mathrm{CuZr}_{2}$ (space group: $14 / \mathrm{mmm}$, number: 139), $\mathrm{Zr}_{6} \mathrm{NiAl}_{2}$ (space group: $P \overline{6} 2 m$, number: 189 ) and $\mathrm{Cu}_{2} \mathrm{ZrAl}$ (space group: $F m \overline{3} m$, number: 225 ) alloys. It can be seen that 

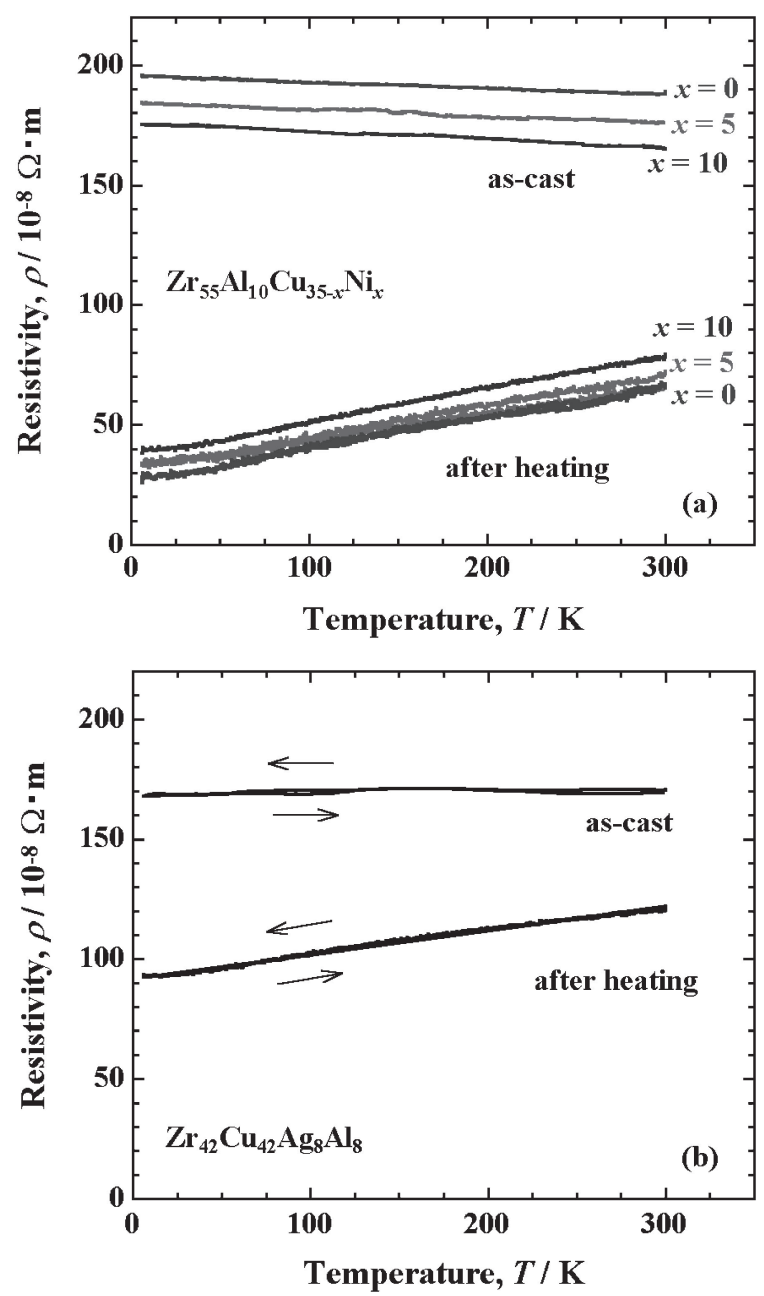

Fig. 5 Temperature dependence of the electrical resistivity of $\mathrm{Zr}_{55} \mathrm{Al}_{10^{-}}$ $\mathrm{Cu}_{35-x} \mathrm{Ni}_{x}(x=0$ and 10$)$ bulk metallic glassy alloys, together with that for the specimens after heating up to $873 \mathrm{~K}$ (a) and those for $\mathrm{Zr}_{42} \mathrm{Cu}_{42} \mathrm{Ag}_{8} \mathrm{Al}_{8}$ (b).

the most of the peak intensities are composed by the $\mathrm{CuZr}_{2}$ phase and that the amount of the $\mathrm{Cu}_{2} \mathrm{ZrAl}$ phase decreases with increasing $x$ content. The patterns for the crystallized $\mathrm{Zr}_{42} \mathrm{Cu}_{42} \mathrm{Ag}_{8} \mathrm{Al}_{8}$ BMG alloy is indexed as a mixed phase of $\mathrm{Cu}_{10} \mathrm{Zr}_{7}$ (space group: $A b a 2$, number: 41), AgZr (space group: $P 4 / n m m$, number: 129 ) and $\mathrm{Cu}_{2} \mathrm{ZrAl}$ (space group: $F m \overline{3} m$, number: 225 ) alloys. The densities of these crystallized specimens are summarized in Table 2, together with those of the as-cast specimens.

Temperature dependences of the electrical resistivity of $\mathrm{Zr}_{55} \mathrm{Al}_{10} \mathrm{Cu}_{35-x} \mathrm{Ni}_{x}(x=0,5$ and 10) BMG alloys are shown in Fig. 5(a), together with those for the specimens after heating up to $873 \mathrm{~K}$ during thermopower experiments. Figure 5(b) indicates those for $\mathrm{Zr}_{42} \mathrm{Cu}_{42} \mathrm{Ag}_{8} \mathrm{Al}_{8}$. The electrical resistivity at room temperature of the $\mathrm{Zr}_{55} \mathrm{Al}_{10} \mathrm{Cu}_{35-x} \mathrm{Ni}_{x}$ BMG alloys are $160-190 \times 10^{-8} \Omega \cdot \mathrm{m}$, and showing a negative coefficient to the temperature derivative, although the $\mathrm{Zr}_{42} \mathrm{Cu}_{42} \mathrm{Ag}_{8} \mathrm{Al}_{8}$ BMG alloy exhibits a slight tendency for a positive coefficient. The behavior of the temperature dependence of the electrical resistivity $\rho$ of amorphous alloys is often discussed in connection with the value of the temperature coefficient of resistivity (TCR). Here, the TCR is defined as $\left(\rho_{(300 \mathrm{~K})}\right)^{-1} \cdot \mathrm{d} \rho \cdot(\mathrm{d} T)^{-1}$. The values of TCR for

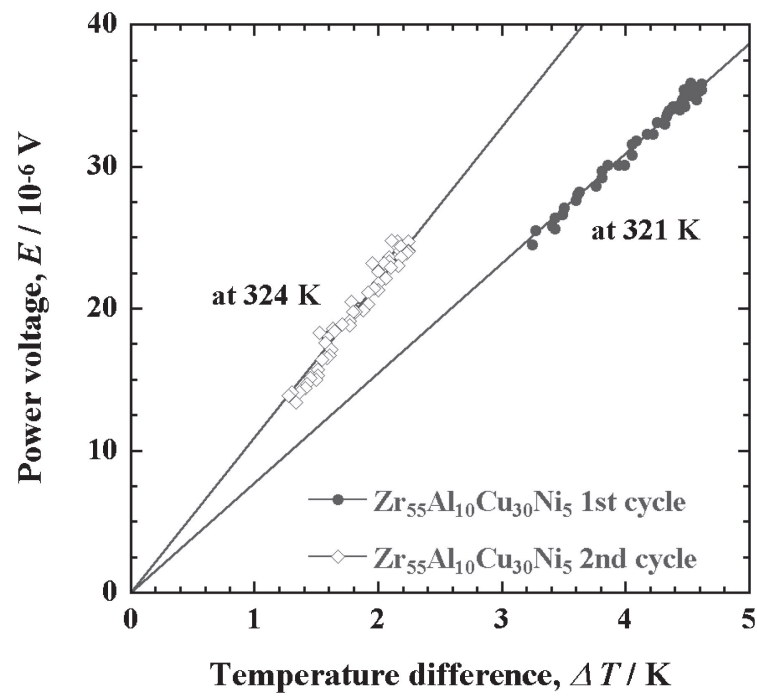

Fig. 6 Examples of the measurements of the thermopower, plot of temperature difference $\Delta T$ versus power voltage $E$ for $x=5\left(\mathrm{Zr}_{55} \mathrm{Al}_{10^{-}}\right.$ $\mathrm{Cu}_{30} \mathrm{Ni}_{5}$ ).

$x=0,5$ and 10 in $\mathrm{Zr}_{55} \mathrm{Al}_{10} \mathrm{Cu}_{35-x} \mathrm{Ni}_{x}$ of the present results are $-13.6,-15.7$ and $-20.5 \times 10^{-5} \mathrm{~K}^{-1}$, respectively. It is considered that the absolute value becomes larger with increasing $\mathrm{Ni}$ content, and the behavior is similar to that in the literature, whereas the electrical resistivity at room temperature is somewhat lower than that of the reported values. ${ }^{15)}$ The electrical resistivity at room temperature of the $\mathrm{Zr}_{42} \mathrm{Cu}_{42} \mathrm{Ag}_{8} \mathrm{Al}_{8} \mathrm{BMG}$ alloy is about $170 \times 10^{-8} \Omega \cdot \mathrm{m}$ and the value of the TCR is $+3.2 \times 10^{-5} \mathrm{~K}^{-1}$.

Figure 6 indicates examples of the measurements of the thermopower, which is given by the temperature derivative of the power voltage between the two probes, for BMG alloy (1st cycle) and its specimens later heated up to $873 \mathrm{~K}$ (2nd cycle) for $x=5\left(\mathrm{Zr}_{55} \mathrm{Al}_{10} \mathrm{Cu}_{30} \mathrm{Ni}_{5}\right)$. The absolute values of the thermopower are obtained after calibration with the value of the thermopower for the probe; in this case, Pt wires were used for the probes. The obtained values measured around room temperature are listed in the Table 1, and they exhibit small positive values in the case of the BMG (as-casting) alloys. It is well known that the sign of the thermopower originates from the sign of the energy derivative of the electronic density of states at the Fermi energy. For the amorphous alloys, there is no sharp structure in the electronic structure in a small energy region, and the electron-phonon scattering contributing to the transport properties is mainly dominated by elastic scattering from the disorder. Positive thermopower is a general feature of metallic glasses with high electrical resistivity from the aspect of the Mooij correlation. ${ }^{16-18)}$ The behavior of the present results of the thermopower and electrical resistivity are in accord with the trend in which the thermopower slightly increases and resistivity slightly decreases with increasing Ni content. This behavior suggests that the transport property is governed by the scattering of the $d$-states in the electronic states. ${ }^{19-21)}$ The explanation of the absolute value of the thermopower of the amorphous transition metals is theoretically more successful than that of the crystalline metals because the scattering mechanism due to the disorder is dominant and there is no 
phonon drag component of the thermopower. For the crystallized specimens, electrical resistivity exhibits normal behavior as metals and alloys, and the thermopower has a positive and larger value than that of the glassy state. The behavior of the thermopower of the crystallized state is more complicated, and in addition, the present specimens consist of three kinds of phases, as shown in Figs. 4(a) and 4(b).

Finally the transport properties between the electrical resistivity and the thermal conductivity are discussed in relation to the free-electron model. In general, the thermal conductivity of the metals is indicated as sum of the electronic and the phonon contributions. The electronic contribution to the thermal conductivity $K_{\mathrm{el}}$ of $\mathrm{BMG}$ is thought to follow the Wiedemann-Franz law, ${ }^{8,9,22-24)}$ and thus it can be estimated as follows:

$$
K_{\mathrm{el}}=L T / \rho,
$$

where $L, T$ and $\rho$ are the Lorenz number $\left(=2.45 \times 10^{-8}\right.$ $\mathrm{W} \Omega \mathrm{K}^{-2}$ ), temperature and electrical resistivity, respectively. Equation (2) means that $K_{\mathrm{el}}$ can be estimated from $\rho$, and the obtained values of $K_{\mathrm{el}}$ are also listed in Table 1. The difference between the total $K$, which is obtained experimentally, and $K_{\mathrm{el}}$ corresponds to the phonon contribution to the thermal conductivity. From the comparison of these values, it is considered that the $K_{\text {el }}$ is dominant even around room temperature, whereas such a situation is natural in the low temperature regions. Similar behavior of the large contribution of $K_{\mathrm{el}}$ to the total thermal conductivity has been reported in Pd-based BMG alloys. ${ }^{89}$ ) It is noted that $K_{\mathrm{el}}$ of the crystallized alloys also accounts for the majority of the total value. This would be due to the condition of the mixed phase or the phases with comparatively close-packed crystal structures, which appear basically in the equilibrium state.

\section{Conclusions}

Thermal diffusivity, electrical resistivity, and thermopower of Zr-based bulk metallic glassy (BMG) alloys of $\mathrm{Zr}_{55^{-}}$ $\mathrm{Al}_{10} \mathrm{Cu}_{35-x} \mathrm{Ni}_{x}\left(x=0,5\right.$ and 10) and $\mathrm{Zr}_{42} \mathrm{Cu}_{42} \mathrm{Ag}_{8} \mathrm{Al}_{8}$ with high glass-forming ability were investigated. Thermal diffusivity is comparatively low at about $2 \times 10^{-6} \mathrm{~m}^{2} \mathrm{~s}^{-1}$, reflecting the aperiodic crystal structure of the $\mathrm{BMG}$, whereas it becomes higher and depends on the alloy compositions after their crystallization. It is considered that the phonon contribution to the thermal conductivity of the BMG alloys is small, based on a comparison with the estimated value of the electronic contribution to the thermal conductivity from the Wiedemann-Franz law. The thermopower of the present $\mathrm{Zr}$-based BMG alloys shows a small positive value at the room temperature, showing the general feature of nonmagnetic amorphous alloys.

\section{REFERENCES}

1) F. Yonezawa: Solid State Phys. Adv. Res. Appl. 45 (1991) 186.

2) A. Inoue, T. Zhang and T. Masumoto: Mater. Trans. JIM 31 (1990) 177-183.

3) A. Inoue, T. Zhang and T. Masumoto: J. Non-Cryst. Solids 156-158 (1993) 473.

4) A. Inoue: Acta Mater. 48 (2000) 279.

5) M. Hasegawa, K. Soda, H. Sato, T. Suzuki, T. Taketomi, T. Takeuchi, H. Kato and U. Mizutani: J. Alloy. Compd. 434-435 (2007) 149.

6) M. Hasegawa, H. Sato, T. Takeuchi, K. Soda and U. Mizutani: J. Alloy. Compd. 483 (2009) 638.

7) S. Hosokawa, N. Happo, H. Sato, M. Taniguchi, T. Ichitsubo, M. Sakurai, E. Matsubara and N. Nishiyama: Mater. Trans. 46 (2005) 2803-2806.

8) M. Yamasaki, S. Kagao and Y. Kawamura: Scr. Mater. 53 (2005) 63.

9) M. Yamasaki, S. Kagao, Y. Kawamura and K. Yoshimura: Appl. Phys. Lett. 84 (2004) 4653.

10) A. Inoue, Y. Kawamura, T. Shibata and K. Sasamori: Mater. Trans. JIM 37 (1996) 1337-1341.

11) A. Inoue, T. Zhang, K. Ohba and T. Shibata: Mater. Trans. JIM 36 (1995) 876-878.

12) Q. K. Jiang, X. P. Nie, Y. G. Li, Y. Jin, Z. Y. Chang, X. M. Huang and J. Z. Jiang: J. Alloy. Compd. 443 (2007) 191.

13) T. Nishi, H. Shibata, H. Ohta, N. Nishiyama, A. Inoue and Y. Waseda: Phys. Rev. B 70 (2004) 174204.

14) T. Nishi, H. Shibata, H. Ohta, O. Haruyama, N. Nishiyama, A. Inoue and Y. Waseda: Mater. Trans. 45 (2004) 2584-2586.

15) D. Okai, T. Fukami, T. Yamasaki, T. Zhang and A. Inoue: Mater. Sci. Eng. A 375-377 (2004) 364.

16) H. Mooij: Phys. Status Solidi A 17 (1973) 521.

17) M. A. Howson and B. L. Gallagher: Phys. Rep. 170 (1988) 265.

18) J. P. Carini, S. R. Nagel, L. K. Varga and T. Schmidt: Phys. Rev. B 27 (1983) 7589

19) B. L. Gallagher and B. J. Hickey: J. Phys. F: Met. Phys. 15 (1985) 911.

20) S. R. Nagel: Phys Rev. Lett. 41 (1978) 990.

21) T. Matsuda, K. Shirai, H. Sato, Y. Yamada and U. Mizutani: Mater. Trans. Eng. A 181-182 (1994) 926.

22) U. Harms, T. D. Shen and R. B. Schwarz: Scr. Mater. 47 (2002) 411.

23) Y. K. Kuo, K. M. Sivakumar, C. A. Su, C. N. Ku, S. T. Lin, A. B. Kaiser, J. B. Qiang, Q. Wang and C. Dong: Phys. Rev. B 74 (2006) 014208.

24) Z. Zhou, C. Uher, D. Xu, W. L. Johnson, W. Gannon and M. C. Aronson: Appl. Phys. Lett. 89 (2006) 031924. 